HRJ

v. 2 n.9 (2021)

Recebido: $21 / 12 / 2020$

Aceito: 22/01/2021

\title{
A vigilância em saúde nos territórios e a pandemia de COVID-19: (A falta de) O papel da Atenção Primária à Saúde
}

\author{
Felipe de Oliveira Lopes Cavalcanti ${ }^{1}$ \\ Carolina Xavier de Bastos²
}

${ }^{1}$ Médico sanitarista, supervisor da residência em Medicina Preventiva e Social da ESCS/FEPECS/GDF, doutor em Saúde Coletiva pelo IMS/UERJ, médico de família e comunidade da SES/DF e docente da Faculdade de Medicina da UnB

${ }^{2}$ Médica, residente em Medicina Preventiva e Social da ESCS/FEPECS/GDF

Novo coronavírus, pandemia, novo normal. Essas palavras que agora parecem uma cantilena retinente ecoada aqui e acolá marcam o final desta década em que nos vimos como que inseridos em um cenário pré-apocalíptico de filmes como Epidemia e Contágio. Desde o início desse turbilhão, vários de nós buscamos entrever possíveis saldos positivos em meio ao avanço de uma doença que, no limite, ameaça nossa existência. Ao fim e ao cabo, teríamos sistemas de saúde mais fortalecidos? Quais seriam as ações centrais tomadas por governos e sociedade no enfrentamento da pandemia? A sanha mercantilizadora arrefeceria, deixando a saúde e as vidas menos expostas às negociatas e à busca de lucro? As vacinas seriam disponibilizadas globalmente e a todas as pessoas independentemente de cor, credo, lugar de moradia e capacidade de pagamento? No momento em que escrevemos este artigo, já nos últimos dias deste atípico ano de 2020, podemos afirmar que está tudo como dantes no quartel de Abrantes.

Em $O$ nascimento da medicina social Foucault ${ }^{1}$ levanta a hipótese de que, ao contrário do entendimento então vigente, o capitalismo opera a passagem de uma medicina individual para uma de caráter coletivo. A partir dos exemplos da Alemanha, França e Inglaterra, o filósofo procura demonstrar como a medicina tornou-se "essencialmente um controle da saúde 
e do corpo das classes mais pobres para torná-las mais aptas ao trabalho e menos perigosas às classes mais ricas" (p. 97). A medicina social inglesa seria o exemplo mais bem acabado e exitoso, realizando "uma medicina assistencial destinada aos mais pobres, uma medicina administrativa encarregada de problemas gerais como a vacinação, as epidemias etc., e uma medicina privada que beneficiava quem tinha meios para pagá-la" (idem). Os sistemas de saúde surgidos a partir do Welfare State seriam responsáveis por fazer funcionar esses três setores da medicina, sob novas formas e articulações.

A vigilância em saúde é o campo de conhecimentos e práticas que mais se identifica com o que Foucault chamou de "medicina administrativa". Com a pandemia de COVID-19, seria natural imaginar que esse campo fosse deveras fortalecido. Neste artigo, pretendemos discutir se esta suposição, aparentemente lógica, realizou-se de fato, no Brasil. Antes, todavia, vamos relembrar um pouco do histórico dessa pandemia.

\section{O SURGIMENTO DO NOVO CORONAVIRUS E SUA DISSEMINAÇÃO}

Em dezembro de 2019 teve início o surto de uma doença respiratória aguda, acometendo pessoas que, em sua maioria, tinham circulado no mercado Huanan, na cidade chinesa de Wuhan, província de Hubei. O primeiro caso oficial foi de um paciente hospitalizado em 12 de dezembro, ainda que estudos retrospectivos remontem à identificação de um caso clínico com sintomas sugestivos da mesma doença já no dia $1^{\circ}$ do mesmo mês ${ }^{2}$. O artigo inaugural publicado sobre a doença descreveu o caso de um paciente hospitalizado em 26 de dezembro, estabelecendo relação filogenética do seu agente etiológico com os coronavírus causadores da Sars e Mers³.

Em 31 de dezembro de 2019, a China comunicou à Organização Mundial de Saúde (OMS) sobre um cluster de casos de pneumonia de causa desconhecida e, em 2 de janeiro de 2020, a OMS comunicou o fato aos parceiros da Global Outbreak Alert and Response 
Network ${ }^{4}$. As informações disponíveis sobre o que aconteceu e como, na sequência, são confusas e às vezes contraditórias. Neste texto, decidimos adotar o que consta como informação oficial da OMS, na última referência citada, cotejando, sempre que considerarmos relevante, com informações de outras fontes.

No dia 11 do mesmo mês de janeiro de 2020, a organização anunciou o sequenciamento genético do novo coronavírus e a mídia chinesa reportou a primeira morte pela doença. Naquele momento ainda não se sabia ao certo se havia transmissão do vírus entre humanos, não havia métodos para identificação do vírus em pessoas e não se conhecia a existência de casos em outros países. Dessa data até o final de janeiro, a OMS anunciou um método de detecção do vírus (13/01), o hoje amplamente conhecido, RT-PCR, além de registrar o informe dos primeiros casos fora da China: Tailândia (13/01), Japão (15/01), Estados Unidos (21/01), França (24/01) e Arábia Saudita (29/01). Naquele momento, ainda restavam dúvidas sobre o potencial de disseminação do vírus e o comitê formado pela OMS, reunido nos dias 22 e 23, decidiu não recomendar que o surto fosse decretado como Emergência de Saúde Pública de Importância Internacional (ESPII). No dia 30 já se contavam 98 casos confirmados fora da China, em 18 países, mas ainda sem nenhuma morte. O cenário e as evidências de transmissão entre humanos gerados a partir da análise de 8 casos em quatro desses países (Alemanha, Japão, Estados Unidos e Vietnam) levaram o comitê da OMS a recomendar à direção da organização que fosse decretada ESPII, o que aconteceu no dia seguinte (31/01). A essa altura, no entanto, o número de casos na China já totalizava 11.791 e 259 mortes $^{5}$ e, apenas 10 dias depois, já havia quase quadruplicado, com 40.171 casos e 908 mortes $^{6}$, apesar de que medidas mais duras tenham se iniciado no país desde a penúltima semana de janeiro, quando mais de 56 milhões de pessoas foram colocadas sob lockdown.

Em 11 de fevereiro, a OMS nomeou a doença causada pelo novo coronavírus como COVID-19 e logo as primeiras mortes fora da China começaram a ser reportadas: Japão 
(13/02), França (14/02) e Taiwan $(16 / 02)^{6}$. Ao final do mês, já existiam casos confirmados em inúmeros países e o número de casos e mortes alcançava as cifras respectivamente de 88.345 e 2.977, sendo a maioria ainda na China. Por outro lado, este país anunciou que as medidas de restrição de circulação, identificação de novos casos com rastreamento e isolamento de contatos começavam a surtir efeito, com o número de novos casos diários caindo de quase 4 mil no início de fevereiro para menos de uma centena no início de maço. O surto pandêmico, no entanto, continuou em rápida progressão, com alto poder de disseminação e crescente número de novos casos e mortes em vários países do mundo. Em 11 de março a OMS declarou o surto de COVID-19 como pandemia ${ }^{4}$ e vários países ampliaram a restrição de viagens internacionais, dentre outras medidas de controle.

Atualmente, contabilizam-se mais de 76 milhões de casos confirmados de COVID-19 em todo o mundo, com quase 1 milhão e 700 mil óbitos ${ }^{7}$, o que coloca a doença, sozinha, como a quinta principal causa de morte se comparados aos dados de mortalidade de 2019, recentemente publicados pela $\mathrm{OMS}^{8}$.

\section{O CORONAVIRUS NO BRASIL}

Ainda em 03 de janeiro de 2020, o Ministério da Saúde (MS) brasileiro fez uma solicitação de esclarecimento à OMS, buscando maiores informações quanto ao novo coronavírus e, com o intuito de monitoramento da dinâmica dos casos em território nacional, foi acionado o Comitê de Monitoramento de Eventos do MS em 10 de janeiro. Já no dia 16 do mesmo mês, o MS publicou um Boletim Epidemiológico onde constavam as primeiras informações sobre o que se sabia sobre o vírus e a doença ${ }^{9}$. Seguindo o anúncio de ESPII pela OMS, o Brasil declarou estado de Emergência de Saúde Pública de Importância Nacional (ESPIN) em 03 de fevereiro ${ }^{10}$. 
O primeiro caso suspeito de COVID-19 no Brasil foi notificado no dia 22 de janeiro e até 21 de fevereiro o MS recebera 154 notificações, todas descartadas ${ }^{11}$. Há uma discussão sobre qual teria sido o primeiro caso de COVID-19 ${ }^{12}$, mas oficialmente o primeiro caso confirmado data de 25 de fevereiro e o segundo no dia 29, ambos no estado de São Paulo e de pacientes provenientes da Itália ${ }^{13,14}$. Na ocasião, o então Ministro da Saúde Luiz Henrique Mandetta ainda minimizava o potencial nefasto do que naquele momento era internacionalmente considerado "apenas" uma Emergência de Saúde Pública de Importância Internacional (ESPII) pela $\mathrm{OMS}^{15}$.

Neste período, o ministério lançou campanha publicitária sobre prevenção ao coronavírus, com orientações sobre lavagem das mãos com água e sabão, uso de álcool a 70\% e não compartilhamento de objetos pessoais. Logo se iniciaram entrevistas coletivas praticamente diárias, a maioria com a presença do então ministro, relatando a situação e as tratativas junto aos Estados e municípios. Além disso, o MS adotou um novo fluxo de consolidação de casos do novo coronavírus, descentralizando a responsabilidade da consolidação das notificações dos casos pelos Estados ${ }^{16}$.

Em 03 de março a imprensa noticiou descontentamento de técnicos do MS com a OMS pelo fato desta ainda não ter decretado pandemia de COVID-19 ${ }^{17}$. Em 5 de março, o Brasil apresentava 8 casos confirmados, divididos entre os estados de São Paulo e Espírito Santo, sendo confirmado pelo MS o primeiro caso de transmissão dentro do país. Em 06 de março, o MS anunciou medidas de reforço à assistência hospitalar, à Atenção Primária à Saúde (APS), a convocação de médicos para o programa Mais Médicos, a organização do fluxo de atendimento a pacientes com doenças crônicas, autorização para uso da telemedicina e ampliação de leitos de Unidades de Terapia Intensiva (UTI).

No momento da declaração do surto de COVID-19 como pandemia pela OMS, em 11 de março, o Brasil contabilizava 52 casos confirmados em 8 estados ${ }^{13}$. Em 17 de março foi 
notificada a primeira morte por coronavírus no país, coincidindo com a publicação pelo Governo Federal da portaria interministerial $n^{\circ} 5$, a qual regulamentava a Lei $n^{\circ} 13.979$ de 6 de fevereiro e versava sobre medidas de isolamento, quarentena e realização compulsória de exames, vacinação e tratamento, dentre outras. Na prática, a regulamentação tornava a recusa à realização das medidas de enfrentamento à emergência de saúde pública passível de enquadramento como crime.

Com a impossibilidade de identificar a origem dos novos casos, o MS reconheceu a transmissão comunitária da COVID-19 em todo o território nacional no dia 20 de março $^{13}$. Em outras palavras, a doença já não estava restrita a pessoas que havia viajado ao exterior e seus contactantes. Neste momento, o número de óbitos já passava de 10.000 no mundo, com 904 casos confirmados e 11 óbitos no Brasil ${ }^{13}$.

Enquanto outros países já haviam restringido a entrada de estrangeiros dos países mais afetados pela COVID-19, apenas em 23 de março o Brasil restringiu a entrada de estrangeiros oriundos da China, Austrália, Japão, vários países da Europa, Malásia e Coréia do Sul. A propósito, uma comitiva presidencial do governo brasileiro aos Estados Unidos entre 7 e 10 de março, com 45 pessoas, resultou em 23 infectados pela COVID-19 ${ }^{18}$.

No momento em que escrevemos esse texto, o portal oficial do Ministério da Saúde registra mais de 186 mil óbitos e mais de 7,2 milhões de casos confirmados. Esses números colocam a COVID-19 como $1^{\text {a }}$ causa de morte no Brasil para o ano de $2020^{19}$.

\section{REMEDIAR É MELHOR QUE PREVENIR}

Durante a pandemia, no Brasil, houve uma inversão do tradicional ditado popular de que "prevenir é melhor que remediar". Apesar da descrição dos acontecimentos acima sugerirem um acompanhamento próximo por parte da equipe técnica do Ministério da Saúde 
em relação à evolução da doença no Brasil e no mundo, os fatos que se seguiram ao diagnóstico dos primeiros casos falam contrariamente à esta suposição.

O Brasil teve um tempo maior para tomar algumas medidas, se comparado a outros países fortemente atingidos pela pandemia. Muito antes do número de casos novos diários atingir a casa do milhar, no dia $1^{\circ}$ de abril - e desde então progrediu para dezenas de milhares - a situação de outros países já era suficientemente grave para alertar-nos da gravidade da situação. Os exemplos da Itália, e depois da Espanha, televisionados diariamente pelos principais grupos de mídia demonstrava a situação dramática de falta de leitos de UTI, carência de profissionais e equipamentos de proteção individual (EPIs). Os meses de janeiro, fevereiro e março teriam sido cruciais para buscar garantir o abastecimento do país, porém o país tardou e teve que disputar no mercado internacional com atores de peso muito maior. Uma análise das notícias, comunicados do Ministério da Saúde e entrevistas do ministro da saúde à época permite inferir que, até meados de março, a atuação do governo era parca, seja no sentido de realizar compras internacionalmente, seja no sentido de estimular a produção nacional.

Ainda assim, diversas medidas foram tomadas por Estados e municípios, mesmo que de forma descoordenada e contra o governo federal, com suspensão das aulas, fechamento temporário do comércio, adoção do uso de máscara, dentre outras. O MS algumas vezes contestou as medidas, noutras se mostrou indiferente. A descoordenação foi sendo progressivamente agravada pelo contexto político federal, com a demissão do ministro Luiz Henrique Mandetta e do ministro que o substituiu, Nelson Teich, menos de 1 mês depois, assumindo o ministério um general sem experiência na gestão do SUS.

Mesmo o ministro Mandetta fez como que uma defesa prévia de possíveis erros, afirmando que sempre haveria engenheiros de obra pronta. "Engenheiros de obra pronta são aqueles que, depois que a obra está pronta, vão lá botar defeito" afirmou em coletiva realizada em 22 de março e em várias outras ocasiões ${ }^{20}$. Certamente a realidade mundial não era simples, 
a procura pelos equipamentos e insumos aumentou drasticamente e havia no cenário atores de maior peso geopolítico em relação ao Brasil. Exemplo cabal foi a retenção pelos Estados Unidos de respiradores artificiais comprados pelo Brasil à China ${ }^{21}$. Todavia, a principal obra para enfrentamento da pandemia já estava pronta e simplesmente não foi devidamente utilizada, nem por Mandetta, nem pelos ministros que o sucederam.

\section{A VIGILÂNCIA EM SAÚDE NOS TERRITÓRIOS}

O Programa Saúde da Família (PSF) foi criado em 1994 e possuía um conjunto de diretrizes quanto à estruturação do trabalho, não apenas médico, mas também de toda a equipe mínima da atenção básica a saúde ${ }^{22}$. A clássica organização do cuidado recortada por grupos populacionais e doenças (gestantes, crianças, hipertensos, diabéticos etc.), com pouco ou nenhum espaço para a demanda espontânea, configurou a melhor realização institucional em grande escala do marco teórico das ações programáticas em saúde ${ }^{23}$. A clínica, nesse modelo, era subsumida pela epidemiologia, na medida em que tais recortes são consequência da definição do que são problemas de saúde pública.

Gastão Wagner, no clássico "Crítica às noções que fundamentam o método de 'Programação em Saúde" 24 criticou frontalmente a proposta das ações programáticas sistematizada nas "Seis teses sobre a ação programática em saúde" 25 . De forma excessivamente sumária, pode-se dizer que Gastão criticava a tentativa de subsumir a produção da vida social e de sua expressão em necessidades de saúde pelos instrumentos da ciência considerados legítimos. No modelo da programação em saúde, acne, varizes, queda de cabelo etc. não seriam objeto de cuidados, pois não estão relacionados a problemas que incidem na mortalidade. Isto é, não são problemas de saúde pública. E não importa o quanto afetem as pessoas individualmente. 
Aliás, no PSF, mesmo a demanda espontânea relacionada a problemas potencialmente objeto de suas ações prioritárias, tinha pouco espaço. Dor no peito, perda de força, crise asmática grave eram quadros para as urgências e emergências. À atenção básica era devida a prevenção de doenças e a promoção da saúde, associando assistência e vigilância de forma exemplar.

Atualmente, muitos temos a percepção de que essa agenda fechada, recortada em dias específicos para pré-natal, puericultura, hipertensos, diabéticos vem num movimento de extinção. A partir da Política Nacional de Atenção Básica (PNAB) de $2011^{26}$ e das ações do ministério desde então, mas também certamente da demanda de cuidados da população, o modelo engessado das ações programáticas tem perdido espaço para o que Schraiber chamou de modelo de consultaçāo ${ }^{27}$. São muitos os relatos de colegas que trabalham Brasil afora no sentido de que há uma crescente sobrecarga, posto que, além das atividades tradicionais centradas na relação entre vigilância e assistência em saúde voltadas aos problemas de saúde pública, há uma pressão generalizada para dar resposta às demandas espontâneas de forma indistinta. Na maioria das vezes em detrimento das ações relacionadas aos programas, especialmente, mas não só, as realizadas fora do consultório. Não há aqui nenhuma defesa à estruturação programática da agenda das equipes. Porém, não é razoável supor que seria possível manter os parâmetros de cobertura estabelecidos na década de 1990 (3.500 pessoas por equipe de atenção primária), parâmetros esses baseados numa determinada lógica de estruturação do trabalho, e ampliar o escopo do trabalho para o atendimento de demandas as mais diversas, mantendo as atividades anteriormente preconizadas. Ao seguir essa diretriz/imposição da gestão, as equipes têm-no feito em substituição às clássicas e também muito importantes atividades de vigilância. Tal fato, associado à redução da presença dos Agentes Comunitários de Saúde nas equipes, à estagnação do crescimento e da qualificação da 
APS que acompanham esses tempos de austeridade fiscal e teto de gastos, têm levado à profunda degradação da clínica, assim como da vigilância em saúde.

Dentre as ações clássicas de vigilância preconizadas pela ação programática em saúde, no antigo PSF, agora denominado Estratégia Saúde da Família, é importante relembrar ainda dois antigos problemas de saúde pública que são seus objetos prioritários: tuberculose e hanseníase. Ambos são doenças transmissíveis de alta relevância por seu impacto na morbimortalidade das populações, sendo alçados a prioridade dentre as questões a serem trabalhadas pelas equipes de atenção primária à saúde desde a criação do PSF. Diagnóstico de casos, educação em saúde, rastreamento de contatos, tratamento supervisionado dentre outras medidas de controle das doenças faziam (fazem) parte da rotina das equipes como ações prioritárias, devendo estar na ordem do dia de sua atuação.

A essa altura, caro leitor, talvez você esteja se perguntando qual a relação disso com a vigilância em saúde da COVID-19 nos territórios? Pode parecer distante, mas os assuntos estão diretamente relacionados. De um lado, é preciso remontar ao tópico anterior desse texto: toda a prioridade do governo federal no enfrentamento da COVID-19, desde a gestão do ministro Mandetta, mas ainda mais aprofundada após sua saída, foi no sentido de comprar respiradores, abrir leitos de UTI e oferecer tratamentos sem comprovação científica, inclusive confundindo profissionais e população sobre um ilusório tratamento precoce ${ }^{28}$. Apesar da publicação das "Recomendações para adequação das ações dos Agentes Comunitários de Saúde frente à atual situação epidemiológica referente ao COVID-19"29 ainda em março de 2020, a tônica do discurso do Ministério da Saúde está centrada no atendimento hospitalar, com pouco ou nenhum foco às ações de vigilância. Mesmo o documento citado, assim como outros destinados à APS, não trazem referência à testagem em massa, rastreamento de contatos, isolamento, quarentena, dentre outras medidas de sucesso adotadas pela Alemanha, China, Coreia do Sul, Japão, Taiwan, Vietnam ${ }^{30}$ dentre outros países que obtiveram bons resultados no controle da 
pandemia. A única medida clara do MS nesse sentido veio apenas 6 meses depois da ampla disseminação da doença: a portaria 2.358/2020, que instituiu incentivo de custeio para ações de rastreamento e monitoramento de casos de COVID-19. Ainda assim, o incentivo foi restrito aos meses de outubro, novembro e dezembro.

Se é verdade que a APS está combalida pela demanda, tendencialmente destinada a funcionar sob a lógica de pronto-atendimento se seguidos os direcionamentos vigentes da política de saúde em âmbito nacional, seguidas por vários Estados e municípios, as equipes de APS têm dado contribuições muito importantes. Não por acaso pipocam exemplos de equipes, municípios e até mesmo Estados que buscaram realizar/estimular ações nos territórios em meio à pandemia, tanto em relação aos casos de COVID-19 em si, quanto em relação a outros efeitos gerados pela pandemia (violência doméstica, sofrimento mental devido ao distanciamento etc.). Mesmo com as ressalvas que possam ser feitas à lógica programática do PSF a partir da leitura biopolítica de Foucault, a APS é a obra que estava pronta, algo degradada pelo contexto, e que foi mal aproveitada, sobretudo pela política de saúde (não) gerida pelo governo federal.

\section{BIBLIOGRAFIA}

1 M. Foucault, "O nascimento da medicina social," em Microfísica do poder, São Paulo, Graal, 1984, pp. 79-98.

2 A. Gruber, "Covid-19: o que se sabe sobre a origem da doença," Jornal da USP, 2020.

3 F. Z. S. Y. B. e. a. Wu, "A new coronavirus associated with human respiratory disease in China.," Nature, pp. 265-269, 2020.

4 Organização Mundial da Saúde, "Listings of WHO's response to COVID-19," Organização Mundial da Saúde, 2020. [Online]. Available: https://www.who.int/news/item/29-06-2020-covidtimeline. [Acesso em 20 Dezembro 2020].

5 "Worldometer," independent digital media company, 2020. [Online]. Available: https://www.worldometers.info/coronavirus/country/china/. [Acesso em 20 Dezembro 2020]. 
6 AlJazeera, “Al Jazeera,” Al Jazeera, 2020. [Online]. Available: https://www.aljazeera.com/news/2020/9/20/timeline-how-the-new-coronavirus-spread. [Acesso em 20 Dezembro 2020].

7 John Hopkins University of Medicine, "COVID-19 Dashboard by the Center for Systems Science and Engineering (CSSE) at Johns Hopkins University (JHU),” 2020. [Online]. Available: https://coronavirus.jhu.edu/map.html. [Acesso em 20 Dezembro 2020].

8 "The top 10 causes of death," 09 Dezembro 2020. [Online]. Available: https://www.who.int/news-room/fact-sheets/detail/the-top-10-causes-of-death. [Acesso em 20 Dezembro 2020].

9 Ministério da Saúde, "Boletim Epidemiológico número 01, volume 51, Situação epidemiológica da febre amarela," 2020.

10 Ministério da Saúde, “Boletime Epidemiológico COE 01, número 01,” 2020.

11 Ministério da Saúde, “Boletim Epidemiológico número 03,” Brasília, 2020.

12 BBC Brasil, "BBC News Brasil," BBC Brasil, 26 Abril 2020. [Online]. Available: https://www.bbc.com/portuguese/brasil-52334034. [Acesso em 20 Dezembro 2020].

13 MINISTÉRIO DA SAÚDE, “Boletim epidemiológico número 06,” 2020.

14 UOL, "Ministério da Saúde confirma segundo caso de coronavírus no Brasil," 29 Fevereiro 2020. [Online]. Available: https://noticias.uol.com.br/saude/ultimasnoticias/redacao/2020/02/29/ministerio-da-saude-confirma-segundo-caso-de-covid-19no-brasil.htm. [Acesso em 20 Dezembro 2020].

15 Congresso em Foco, “Congresso em Foco,” UOL, 26 Fevereiro 2020. [Online]. Available: https://congressoemfoco.uol.com.br/saude/ao-vivo-ministro-da-saude-da-entrevistasobre-coronavirus-no-brasil/. [Acesso em 20 Dezembro 2020].

16 CONASS, “CONASS," 02 Março 2020. [Online]. Available: https://www.conass.org.br/ministerio-da-saude-adota-novo-fluxo-de-consolidacao-decasos-de-coronavirus/. [Acesso em 20 Dezembro 2020].

17 FOLHA DE SÃO PAULO, “Governo se irrita com a OMS e diz que já há transmissão em todos os continentes," 03 Março 2020. [Online]. [Acesso em 20 Dezembro 2020].

18 Estadão, “A comitiva presidencial infectada pelo coronavírus,” 20 Março 2020. [Online]. Available: https://www.estadao.com.br/infograficos/politica,a-comitiva-presidencialinfectada-pelo-coronavirus, 1084402. [Acesso em 20 Dezembro 2020].

19 UOL, "Covid-19 já é a maior causa de mortes no Brasil registrada em um único ano," 15 Setembro 2020. [Online]. Available: https://noticias.uol.com.br/saude/ultimasnoticias/redacao/2020/09/15/com-133-mil-obitos-covid-ja-tem-recorde-como-causamorte-no-pais-em-um-ano.htm. [Acesso em 20 Dezembro 2020].

20 Farol da Bahia, "Ministro da Saúde compara jornal O Globo com "engenheiros de obra pronta"," 22 Março $2020 . \quad$ [Online]. Available: https://www.faroldabahia.com.br/noticia/ministro-da-saude-compara-jornal-o-globocom-engenheiros-de-obra-pronta. [Acesso em 20 Dezembro 2020]. 
21 O Globo, "Carga chinesa com 600 respiradores artificiais é retida no EUA e não será enviada ao Brasil," 03 Abril 2020. [Online]. Available: https://oglobo.globo.com/sociedade/carga-chinesa-com-600-respiradores-artificiaisretida-nos-eua-nao-sera-enviada-ao-brasil-24349142. [Acesso em 20 Dezembro 2020].

22 T. Franco e E. Merhy, "PSF: CONTRADIÇÕES DE UM PROGRAMA DESTINADO À MUDANÇA DO MODELO TECNOASSISTENCIAL," em O TRABALHO EM SAÚDE: Olhando e experienciando o SUS no cotidiano, São Paulo, Hucitec, 2003, pp. 34-55.

23 L. Schraiber, Programação em Saúde Hoje, São Paulo: Hucitec, 1993.

24 G. Wagner, "Crítica às noções que fundamentam o método de "Progrmação em Saúde"," em A saúde pública e a defesa da vida, São Paulo, Hucitec, 2006, pp. 55-88.

25 R. B. Gonçalves, L. Schraiber e M. I. Nemes, "Seis teses sobre a ação programática em saúde,” em Programação em Saúde Hoje, São Paulo, Hucitec, 1993, pp. 37-64.

26 BRASIL. Ministério da SAúde, Secretaria de Atenção à Saúde. Departamento de Atenção Básica., Política Nacional de Atenção Básica, Brasília: Ministério da Saúde, 2012.

27 L. Schraiber, "Programação hoje: a força do debate," em Programação em saúde hoje, São Paulo, Hucitec, 1993, pp. 11-36.

28 A. d'Ávila e M. Melo, "O Astronauta e a Jabuticaba," Arq Bras Cardiol, pp. 0-0, Ahead print 2020.

29 Ministério da Saúde, "Ministério da Saúde," Março 2020. [Online]. Available: http://www.saudedafamilia.org/coronavirus/informes_notas_oficios/recomendacoes_ade quacao_acs_versao-001.pdf. [Acesso em 20 Dezembro 2020].

30 BBC Brasil, "5 locais com estratégias bem-sucedidas de combate ao coronavírus," 30

] Março 2020. [Online]. Available: https://www.bbc.com/portuguese/internacional52090542. [Acesso em 20 Dezembro 2020]. 